\title{
Refeeding syndrome and infective complications in patients with anorexia nervosa
}

\author{
A. N. De Silva ${ }^{1}$, K. H. Smith ${ }^{1}$, F. W. Thursby-Pelham ${ }^{2}$, T. R. Smith ${ }^{2}$ and M. A. Stroud ${ }^{1}$ \\ ${ }^{1}$ Institute of Human Nutrition, Southampton and Southampton University Hospital NHS Trust, UK and ${ }^{2}$ Royal Bournemouth \\ NHS Foundation Trust, UK
}

The refeeding syndrome (RFS) is a potentially lethal condition that results in severe electrolyte and fluid shifts associated with metabolic abnormalities in malnourished patients undergoing refeeding from whatever route. Critically malnourished patients with anorexia nervosa (AN) admitted to hospital for feeding are at particularly high risk of developing RFS. Our approach to managing such patients is very cautious, initially using very slow NG feeding, providing $5-10 \mathrm{ml} / \mathrm{h}$ of $1 \mathrm{kcal} / \mathrm{ml}$ standard complete feed, increasing by $10 \mathrm{ml} / \mathrm{h}$ every $24 \mathrm{~h}$ if there is no evidence of RFS until meeting estimated needs (BMR $+20 \%)$. All patients also have prior administration of IV pabrinex and electrolyte restoration throughout feeding. Our goal is 'metabolic stabilisation' by which we mean normalisation of blood sugars, ability to increase energy intake without electrolyte problems and return of appetite. We do not aim for an early increase in weight. We present our experience of managing AN patients using these methods.

Patients with AN admitted between April 2006 and February 2007 were identified from database records. Notes and pathology results were reviewed.

Fourteen patient episodes (11 female) in 12 patients with AN were admitted in this 10-month period. Median age was 23 years (19-47), and mean BMI on admission was $13.15 \pm 1.42$. The median time to achieve stabilisation and discharge was 12 days (7-50 days). Mean weight loss in the 6 months prior to admission was $21 \%$ of body weight and a further $0.7 \mathrm{~kg}$ on average was lost during admission. Eight were discharged as in-patients to an Eating Disorder Service, five to home with psychiatric input and one died in hospital.

Electrolyte changes were common (Table 1). Seven patients showed impaired renal function and 11 showed impaired liver function. Four patients developed severe infection (three pneumonia, one C Diff), showing paradoxical changes in infective markers. Three of these were hypothermic $\left(<35^{\circ} \mathrm{C}\right)$, two were neutropenic $(\mathrm{WCC}<0.5)$ and all four were severely hypoglycaemic $(\mathrm{BM}<1.6)$.

Despite caution in feeding, these data show several patients developed electrolyte changes of RFS and their management may be complicated by renal impairment.

We particularly wish to highlight their propensity to infection without showing increases in temperature, white count or CRP. Although hypoglycaemia and hypothermia are well-recognised markers of infection in malnourished individuals in developing Countries, these paradoxical changes are not well recognised in the UK and possibly contributed to a delay in diagnosis of infection in the patient who died.

Table 1. Electrolyte data from 14 patient episodes

\begin{tabular}{lcc}
\hline & On admission $N(\%)$ & During admission* $N(\%)$ \\
\hline Hyponatraemia $(\mathrm{Na} 130 \mathrm{mmol})$ & $7(50)$ & $3(21)$ \\
Hypokalaemia (K 3.5 mmol) & $7(50)$ & $3(21)$ \\
Hypocalcaemia (corrected Ca $2.15 \mathrm{mmol})$ & $4(29)$ & $7(50)$ \\
Hypomagnesaemia $(\mathrm{Mg} \mathrm{0.74} \mathrm{mmol)}$ & $7(50)$ & $6(43)$ \\
Hypophosphataemia $\left(\mathrm{PO}_{4} 0.78 \mathrm{mmol}\right)$ & $8(57)$ & $6(43)$ \\
\hline
\end{tabular}

* Normal on admission. 